\title{
Voltammetric Determination of Amoxicillin Using a Reduced Graphite Oxide Nanosheet Electrode
}

\author{
Thi Hai Yen Pham $\mathbb{D}^{1},{ }^{1}$ Thi Trang Mai, ${ }^{2}$ Hoang Anh Nguyen, ${ }^{1}$ Thi Thu Hien Chu, ${ }^{3}$ \\ Thi Thu Ha Vu $\mathbb{1}^{1},{ }^{1,4}$ and Quoc Hung Le ${ }^{1}$ \\ ${ }^{1}$ Institute of Chemistry, Vietnam Academy of Science Technology, 18 Hoang Quoc Viet, Cau Giay, Hanoi 100000, Vietnam \\ ${ }^{2}$ VNU University of Science Hanoi, 19 Le Thanh Tong, Hoan Kiem, Hanoi 100000, Vietnam \\ ${ }^{3}$ Department of Chemistry, National University of Civil Engineering (NUCE), 55, Giai Phong, Hai Ba Trung, \\ Hanoi 100000, Vietnam \\ ${ }^{4}$ University of Science and Technology of Hanoi (USTH), Vietnam Academy of Science and Technology, 18 Hoang Quoc Viet, \\ Cau Giay, Hanoi 100000, Vietnam
}

Correspondence should be addressed to Thi Hai Yen Pham; haiyen25986@gmail.com

Received 25 September 2020; Revised 14 October 2020; Accepted 15 April 2021; Published 28 April 2021

Academic Editor: Alessandro Buccolieri

Copyright (c) 2021 Thi Hai Yen Pham et al. This is an open access article distributed under the Creative Commons Attribution License, which permits unrestricted use, distribution, and reproduction in any medium, provided the original work is properly cited.

\begin{abstract}
A reduced graphite oxide nanosheet electrode (RGOnS) was prepared as a sensor for amoxicillin (AMX) detection, an antibiotic commonly used in the livestock farm, by the square-wave adsorptive stripping voltammetry technique. Graphite oxide with nanosheet shape was produced from a graphite electrode by a chronoamperometry process at $5 \mathrm{~V}$ and then an electrochemical reduction process was carried out to form RGOnS with restored long-range conjugated networks and better conductivity. The electrodes were characterized by SEM, EDX, and FTIR spectroscopy. The RGOnS electrode prepared at an optimal reduction potential of $-1 \mathrm{~V}$ for $120 \mathrm{~s}$ exhibits a larger electrochemical active surface area, and the obtained oxidation signal of AMX is approximately ten times higher than that of the pristine graphite electrode. The analytical conditions such as the $\mathrm{pH}$ of electrolyte and accumulation time were optimized. The calibration curve built under the optimal conditions provided a good linear relationship in the range of AMX concentration from $0.5-80 \mu \mathrm{M}$ with the correlation coefficient of 0.9992 . The limit of detection was calculated as $0.193 \mu \mathrm{M}$. Satisfactory results are obtained from the detection of the AMX in different samples using the prepared electrode.
\end{abstract}

\section{Introduction}

Since the first discovery in Beecham Research Laboratories in 1972, amoxicillin, one of the penicillin-derived antibiotics, has been universally used to treat common infectious diseases in humans such as otitis, pneumonia, and genital diseases [1-3]. This kind of antimicrobial drug is also employed in food animal production to prevent infections and boost the growth of animals [4-6]. Accordingly, amoxicillin can be easily released to the environment, such as water body from human excretion, wastewater from food animal production, and hospital wastewater discharges [7-9] due to incomplete waste water treatment. Despite the crucial role of this antibacterial drug, amoxicillin is considered a harmful substance to the ecosystem when it is introduced to the environment. Like other antibiotic substances, the contamination of amoxicillin in the environment, even at a low level, gives rise to the growth of antibiotic-resistant bacteria, which leads to potential risk to human life and livestock [4, 10-12]. Therefore, it is necessary to establish rapid and sensitive methods for the monitoring of amoxicillin at the trace level in the aquatic environment. Apart from common advanced methods for amoxicillin detection such as high-performance liquid chromatography (HPLC) with fluorescence detector, HPLC with ultravioletvisible detector, chemiluminescence, high-performance 
liquid chromatography-tandem mass spectrometry, and ultra performance liquid chromatography-mass spectrometry [13-16]; electrochemical methods have been widely applied in the analysis of antibiotics in real samples in the recent decades because of its advantages such as low cost, simple operation, fast measurement, and good sensitivity and selectivity [17]. Additionally, electrochemical methods can be easily performed for quick analysis of contaminants on-site [18].

In the electrochemical method, working electrodes play a significant role in the analytical measurement because the reduction-oxidation reaction of analytes takes place on the electrode surface. Therefore, scientists have attempted to modify the electrode by advanced methods with the aim of enhancing the analyte signals. Recently, numerous studies have applied nanocarbon-based materials (carbon nanotubes, graphene, graphene oxide) to electrode modification as medical, biological sensors because of their unique physical-chemical properties such as a large electroactive surface area, excellent electron transfer, good electrocatalytic properties, and high chemical resistance [17, 19]. Carbon nanotubes were reported as the electrode material for the detection of biological substances such as antibiotics, glucose, ascorbic acid, dopamine, and uric acid [20-23]. Moreover, the combination of graphene with other metals, metal oxides, or polymers has also been employed in the quantification of some antibiotics such as cloxacillin and chloramphenicol antibiotic in milk samples [24, 25].

Amoxicillin is an electroactive species and can therefore be quantified by electrochemical methods. The electrochemical oxidation of AMX was proposed by some authors $[26,27]$, where the $-\mathrm{OH}$ group attached to the aromatic ring donates one electron to form the $>\mathrm{C}=\mathrm{O}$ group. Due to the advantages of nanocarbon mentioned above, various applications of nanocarbon-based materials in electrode modification to improve the sensitivity of AMX detection were reported. In 2009, Behzad Rezaei and Sajjad Damiri modified glassy carbon substrate by multiwall carbon nanotubes to detect amoxicillin in pharmaceutical and human urine samples [28]. The composite material of carbon nanotubes and gold nanoparticles was employed in the determination of amoxicillin in bovine milk by Muhammad et al. [29]. Graphene and graphene oxide decorated by metal nanoparticles such as gold, palladium, and copper were investigated in some previous studies for the enhancement of amoxicillin electrochemical signals $[30,31]$. In addition, many organic substances containing functional groups that increased the binding ability with AMX were used to modify electrode surfaces along with nanocarbon. Deroco et al. focused on the modification of the glassy carbon electrode (GCE) by carbon black attached to the di-hexadecyl phosphate membrane [32]. In Deroco's study, when the unmodified GCE was used, no AMX oxidation process was observed; however, a well-defined oxidation peak for AMX was obtained using the modified electrode due to its electrochemical catalytic activity and strong interaction with AMX.

In many studies [28, 29, 32-37], the nanocarbonmodified electrodes were prepared by dip-coating or drop- casting methods. These kinds of modifications can lead to unstable bonding between modifiers and the substrate and, therefore, restrict the electron transfer in the redox reaction and the signal of desirable analytes. In this study, with the purpose to improve the electron transfer and the stability, reduced graphite oxide nanosheets were produced directly by the electrochemical expansion of the graphite electrode surface using a rapid, simple, and green electrochemical method. The modified electrode was first applied as an effective electrochemical sensor for amoxicillin detection.

\section{Experiments}

\subsection{Reagents and Apparatus}

2.1.1. Reagents. Amoxicillin trihydrate $\left(\mathrm{C}_{16} \mathrm{H}_{19} \mathrm{~N}_{3} \mathrm{O}_{5} \mathrm{~S} \cdot 3 \mathrm{H}_{2} \mathrm{O}\right.$, 98.0\%) was purchased from bioWorld, USA. $\mathrm{H}_{2} \mathrm{SO}_{4}(98.0 \%), \mathrm{H}_{3} \mathrm{PO}_{4}(85 \%), \mathrm{KOH}(\geq 85.0 \%)$, $\mathrm{KH}_{2} \mathrm{PO}_{4}(\geq 99.5 \%)$, and $\mathrm{K}_{2} \mathrm{HPO}_{4}(\geq 98.0 \%)$ were supplied by Merck (Germany), and $\mathrm{K}_{3}\left[\mathrm{Fe}(\mathrm{CN})_{6}\right](\geq 99.0 \%)$ was obtained from Sigma-Aldrich. All chemicals and reagents were of analytical grade and used without further purification.

A $0.5 \mathrm{M} \mathrm{H}_{2} \mathrm{SO}_{4}$ solution used as a reagent for graphite surface expansion and reduction of the graphite oxide nanosheet electrode was diluted from $98 \% \mathrm{H}_{2} \mathrm{SO}_{4}$ with double distilled water. Phosphate buffer solutions (PBS) with different $\mathrm{pH}$ values from 6.0 to 10.0 were prepared from $0.2 \mathrm{M} \mathrm{KH}_{2} \mathrm{PO}_{4}, \mathrm{~K}_{2} \mathrm{HPO}_{4}$ in double distilled water, and the $\mathrm{pH}$ was adjusted by adding $1.0 \mathrm{M} \mathrm{KOH}$ or $1.0 \mathrm{M} \mathrm{H}_{3} \mathrm{PO}_{4}$ solutions. The buffer solutions were used as a supporting electrolyte in amoxicillin (AMX) detection.

$0.5 \mathrm{mM}$ and $5 \mathrm{mM}$ AMX stock solutions were prepared by dissolving AMX powder in double distilled water. Standard solutions were prepared fresh daily just before use by dilution of the stock solution in PBS.

2.1.2. Apparatus. The surface of the electrodes was examined using field emission scanning electron microscopy (FESEM) (Hitachi S-4800; Japan) at different magnifications and energy dispersive X-ray (EDX) spectra (Horiba 7593-H; England). Fourier transform infrared spectra (FTIR) were obtained on a Spectrum Two FTIR spectrometer (PerkinElmer 102717; UK).

Electrochemical measurements were performed with a custom-made multifunctional potentiogalvanostat manufactured in the Institute of Chemistry, Vietnam Academy of Science and Technology, Hanoi, Vietnam. The electrochemical system was established with three electrodes, where the platinum wire and $\mathrm{Ag} / \mathrm{AgCl}$ electrode were used as a counter electrode and a reference electrode, respectively; the working electrodes were fabricated electrodes such as graphite electrode (GE), graphite oxide nanosheet electrode (GOnS), and reduced graphite oxide nanosheet electrode (RGOnS). Electrochemical characteristics of electrodes were investigated by cyclic voltammetry $(\mathrm{CV})$ in $0.1 \mathrm{M} \mathrm{PBS}$ at $\mathrm{pH}$ 7.0 containing $5 \mathrm{mM} \mathrm{K}_{3}\left[\mathrm{Fe}(\mathrm{CN})_{6}\right]$ and in the analyte. The ability of fabricated electrodes for AMX detection was explored by the square-wave adsorptive stripping voltammetry (SWAdSV) technique in PBS solutions containing AMX. 
2.2. Preparation and Characterization of Graphite Oxide Nanosheet Electrode (GOnS) and Reduced Graphite Oxide Nanosheet Electrode (RGOnS). The disk graphite electrode (99.9\% graphite, diameter of $3.5 \mathrm{~mm}$; Japan) was polished with 3000 and 5000 grit sandpaper to get a flat and smooth surface and rinsed with double distilled water. Then, the ultrasonication of the electrode in ethanol $90 \%$ was carried out to eliminate potential contaminants. After rinsing with double distilled water, the electrode surface was electrochemically expanded by the potentiostatic technique at $5 \mathrm{~V}$ potential for $1 \mathrm{~s}$ in $0.5 \mathrm{M} \mathrm{H}_{2} \mathrm{SO}_{4}$ solution to obtain a graphite oxide nanosheet electrode. After that, the expanded electrode was reduced by applying a constant potential for $120 \mathrm{~s}$ to form a reduced graphite oxide nanosheet electrode named RGOnS.

2.3. Preparation of Real Samples. Distilled water, tap water, West Lake water, and domestic wastewater samples were collected and stored at $4^{\circ} \mathrm{C}$. After filtration, the samples were spiked with a known amount of AMX. To prepare the drug sample solution, the drug powder containing $500 \mathrm{mg}$ AMX in a capsule was finely ground in an agate mortar, then extracted in methanol/water $(1: 1, \mathrm{v} / \mathrm{v})$ solution under the ultrasonic condition for $30 \mathrm{~min}$. After filtration to remove insoluble substances, the extract obtained was made up to $500 \mathrm{~mL}$ in a volumetric flask to obtain a drug sample solution. The AMX concentration in spiked samples and the drug sample solution was determined by the standard addition method.

All experiments in this study were performed at room temperature $\left(25 \pm 1^{\circ} \mathrm{C}\right)$.

\section{Results and Discussion}

3.1. Surface Properties of Graphite Oxide Nanosheet Electrode and Reduced Graphite Oxide Nanosheet Electrode. The surface morphologies of the graphite and graphite oxide nanosheet electrodes were characterized by SEM.

Figure 1(a) shows a smooth and homogenous surface of the graphite electrode. In this image, scattered narrow cracks between graphite layers are clearly observed that exhibits a tight stacking of layers as a feature of the graphite structure. When the graphite electrode was oxidized by applying a potential of $5 \mathrm{~V}$ in $0.5 \mathrm{M} \mathrm{H}_{2} \mathrm{SO}_{4}$ solution to produce GOnS, graphite layers expanded and isolated to form graphite oxide nanosheets on the surface electrode. The obtained GOnS surface is well observed with individual flakes consisting of multiple nanosheet structure (Figures 1(b) and 1(d)). Under the magnification of $80.0 \mathrm{k}$ (Figure 1(d)), the extremely thin shape of graphite oxide sheets with a few nanometers thick are clearly seen; and the distance between flakes is estimated to be from tens to several hundreds of nanometers. After the electrochemical reduction of GOnS to form RGOnS, the multiple nanosheet structure still remained on the electrode surface that is exhibited by the similar morphology in the SEM images of RGOnS (Figure 1(c) and 1(e)) to GOnS in the same magnifications. The great formation of multiple nanosheet structure could cause a significant increase in the specific surface area of modified electrodes compared with to the original one, which would be beneficial for the enhancement of analyte electrochemical signals.
The mechanism of expansion was proposed by Parvez in 2013 and 2014, and $Y u$ in 2015. According to the studies, the electrolysis of water at the high applied voltage produces hydroxyl ions $\left(\mathrm{OH}^{-}\right)$at the edge sites and grain boundaries of the graphite electrode. The interaction of two vicinal - $\mathrm{OH}$ groups can form epoxide rings or be oxidized to create carbonyl groups. Their formation expands the graphite layers leading to the intercalation of $\mathrm{H}_{2} \mathrm{O}, \mathrm{SO}_{4}{ }^{2-}$ into the lattice network. Then, the gaseous $\mathrm{O}_{2}$ and $\mathrm{CO}_{2}$ generation inside the lattice network through the oxidation reaction efficiently support the expansion of graphite nanolayers [38-40].

The element percentage at the electrode surface was estimated from EDX spectra, as shown in Figure 2. While the graphite electrode contained 100\% carbon, the EDX spectra of both GOnS and RGOnS indicate the presence of oxygen in the composition after the oxidation of GE in a $0.5 \mathrm{M} \mathrm{H}_{2} \mathrm{SO}_{4}$ solution, which was attributed to the formation of oxygen functional groups. The proportion of oxygen existing on the surface of GOnS was up to $13.06 \%$. After undergoing a reduction at $-1 \mathrm{~V}$ for $120 \mathrm{~s}$, the percentage of oxygen considerably decreased by nearly one-third to $9.48 \%$. As observed in the spectra, a sulfur element was present in a small proportion on GOnS and RGOnS electrode surfaces, which is due to the intercalation of sulfate ions $\left(\mathrm{SO}_{4}{ }^{2-}\right)$ within graphitic layers during the expansion. After the process, a small amount of sulfate ions still retained or C-S bonds were formed on the electrode surface. This phenomenon is in agreement with previous studies [41, 42].

The FTIR spectra of the electrode surface were used to investigate the change in the chemical structure before and after the electrochemical modification. Figure 2(b) depicts the FTIR spectra of GE, GOnS, and RGOnS. As observed, the peaks of unmodified graphite are not clearly seen; while in GOnS and RGOnS spectra, some typical peaks are well defined with noticeably high intensities. The peak at $3443.9 \mathrm{~cm}^{-1}$ attributed to $\mathrm{O}-\mathrm{H}$ stretching vibration dramatically increased after the GE oxidation, which reveals the remarkable formation of $\mathrm{C}-\mathrm{O}-\mathrm{H}$ groups on the $\mathrm{GOnS}$ surface $[43,44]$. The same peak was also acquired in the RGOnS spectrum, but the peak intensity was slightly lower because an amount of $\mathrm{C}-\mathrm{O}-\mathrm{H}$ group could be electrochemically reduced to $\mathrm{C}-\mathrm{C}$ or $\mathrm{C}=\mathrm{C}$. This restoration of $\mathrm{C}=\mathrm{C}$ bonding on RGOnS was confirmed by a slight increase in peak intensity at $1635 \mathrm{~cm}^{-1}(\mathrm{C}=\mathrm{C}$ stretching) compared with that of GOnS. The peaks at $1207 \mathrm{~cm}^{-1}$ and $1059 \mathrm{~cm}^{-1}$ appeared on the GOnS spectrum referring to the stretching of $\mathrm{C}-\mathrm{O}$ in epoxy and alkoxy groups [45], while these peaks mostly disappeared on the RGOnS spectrum after the reduction of GOnS. The FTIR spectra prove the successful reduction of GOnS to restore $\mathrm{C}=\mathrm{C}$ bonding ( $\pi$ electron conjunction) in the lattice network of RGOnS that facilitated the electron transfer in the AMX oxidation in further experiments.

3.2. Electrochemical Properties of GOnS and RGOnS Electrodes. Electrochemical properties of modified electrodes (GOnS and RGOnS) were evaluated by cyclic 


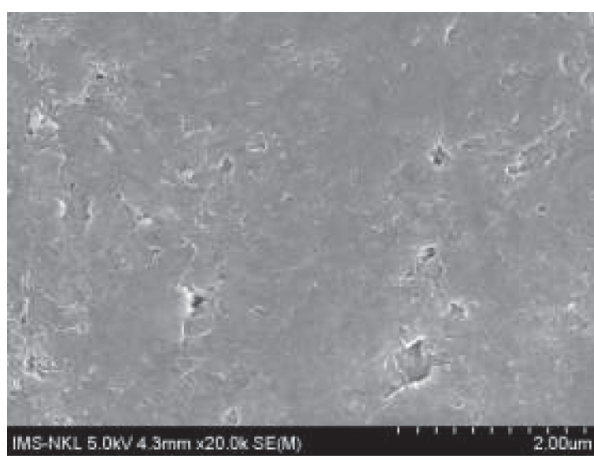

(a)

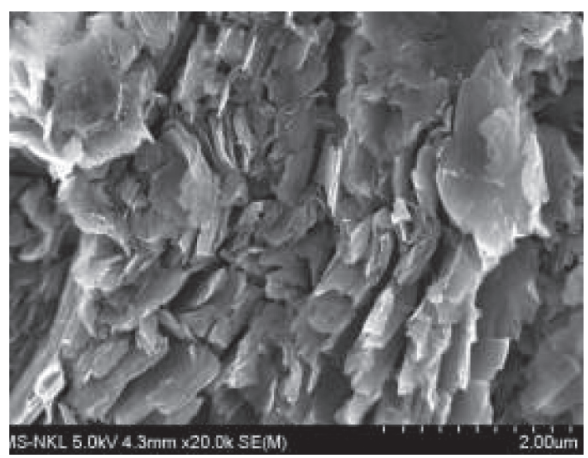

(c)

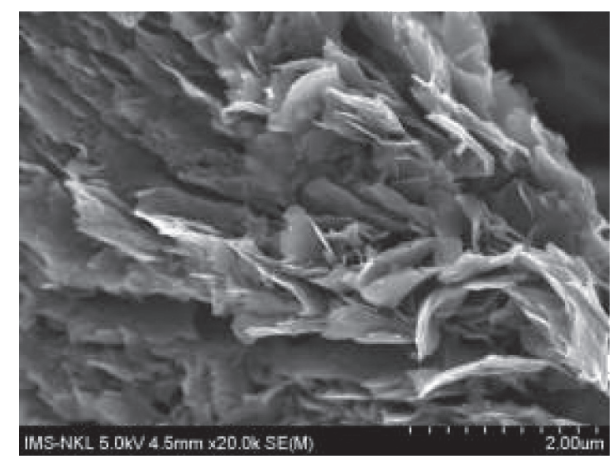

(b)

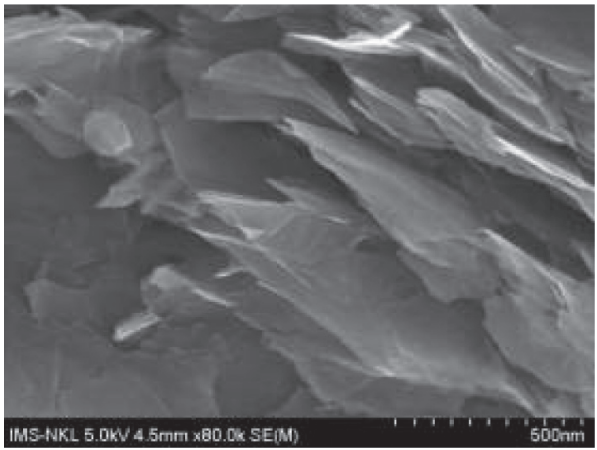

(d)

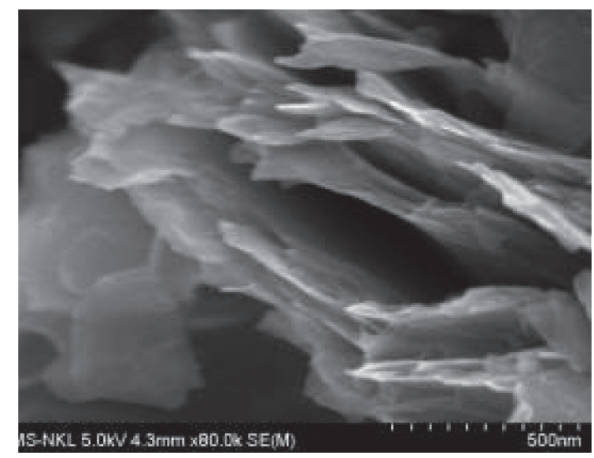

(e)

FIGURE 1: SEM images of graphite electrode (a), graphite oxide nanosheet electrode (b, d), and reduced graphite oxide nanosheet electrode (c, e) at different magnifications.

voltammetry of redox probe $\mathrm{Fe}(\mathrm{CN})_{6}{ }^{3-/ 4-}$, which is shown in Figure 3. It is notable that reversible cyclic voltammograms (CVs) were acquired when using graphite and RGOnS electrodes with $\mathrm{I}_{\mathrm{pc}} / \mathrm{I}_{\mathrm{pa}} \approx 1$ (Figure $3(\mathrm{a})$ ). The reversible characteristic of the redox probe $\mathrm{Fe}(\mathrm{CN})_{6}{ }^{3-/ 4-}$ on RGOnS was also displayed through the linear increase of peak height with the increase of the square root of scan rate $\left(v^{1 / 2}\right)$ in both cathode and anode reactions $\left(R_{\text {cathode }}^{2}=0.9968\right.$, $R_{\text {anode }}^{2}=0.9901$ ) (Figure 3(b)). Meanwhile, CVs of GOnS (Figure 3(a) inset) show a high reduction current attributed to the simultaneous reductions of $\mathrm{Fe}^{3+}$ and the oxidants formed on the GOnS surface after the expansion. The overlapping of these reactions made the reduction peak of $\mathrm{Fe}^{3+}$ indistinct.

Due to the above characteristics, the electrochemical reaction can be considered a diffusion-controlled process; thus, the electrochemical redox reaction of $\mathrm{Fe}(\mathrm{CN})_{6}{ }^{3-/ 4-}$ couple obeys the Randles-Sevcik equation, and the electrochemical active surface area (ECSA) of these electrodes was calculated via this equation $[46,47]$ based on the reduction peak of $(\mathrm{FeCN})_{6}{ }^{3-}$. The calculated ECSA for the RGOnS electrode is approximately 1.3 times higher than that for the graphite electrode.

Figure 3(a) indicates that there were an increase in the peak height and a decrease in the difference of peak potentials $\left(\Delta \mathrm{E}_{\mathrm{p}}\right)$ observed in the $\mathrm{CV}$ of the RGOnS electrode in comparison with the original graphite electrode. These changes were resulted from the higher electrochemical active surface area as well as the faster electron transfer on the RGOnS electrode. The growth of ECSA can be explained by the formation of nanosheet on the electrode surface. Obviously, each nanosheet has similar properties as reduced 


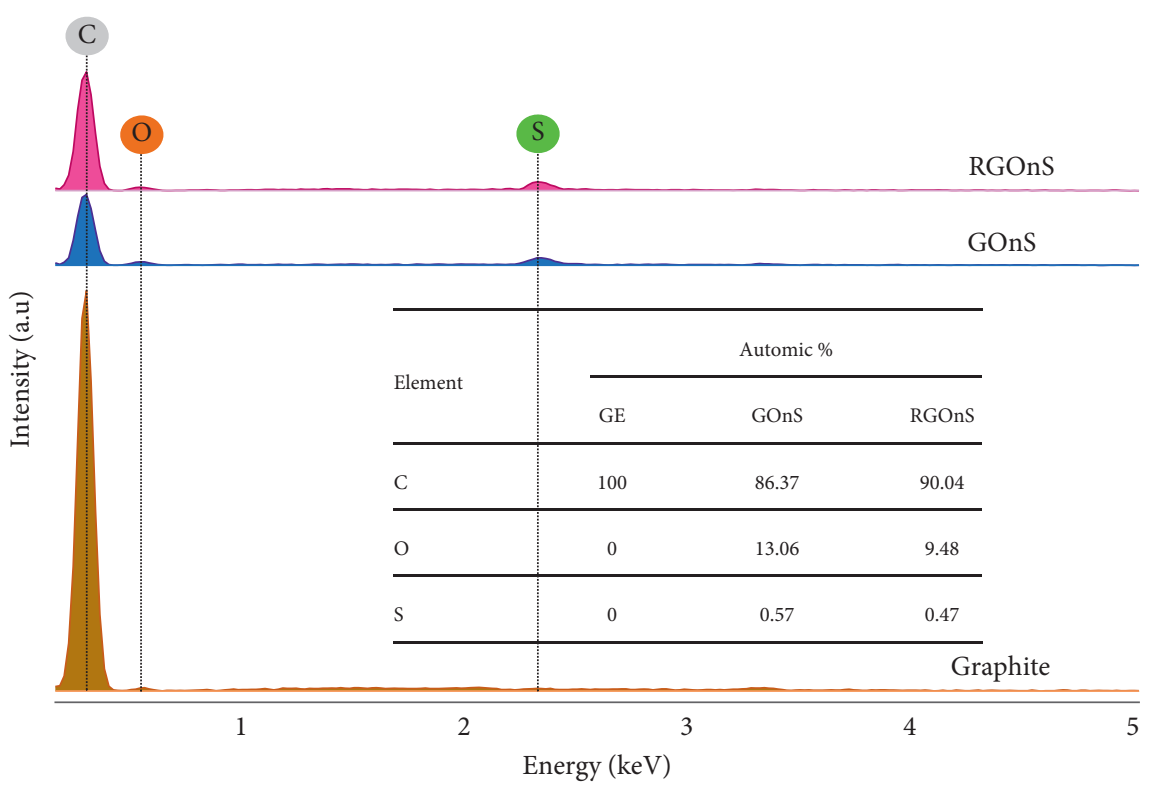

(a)

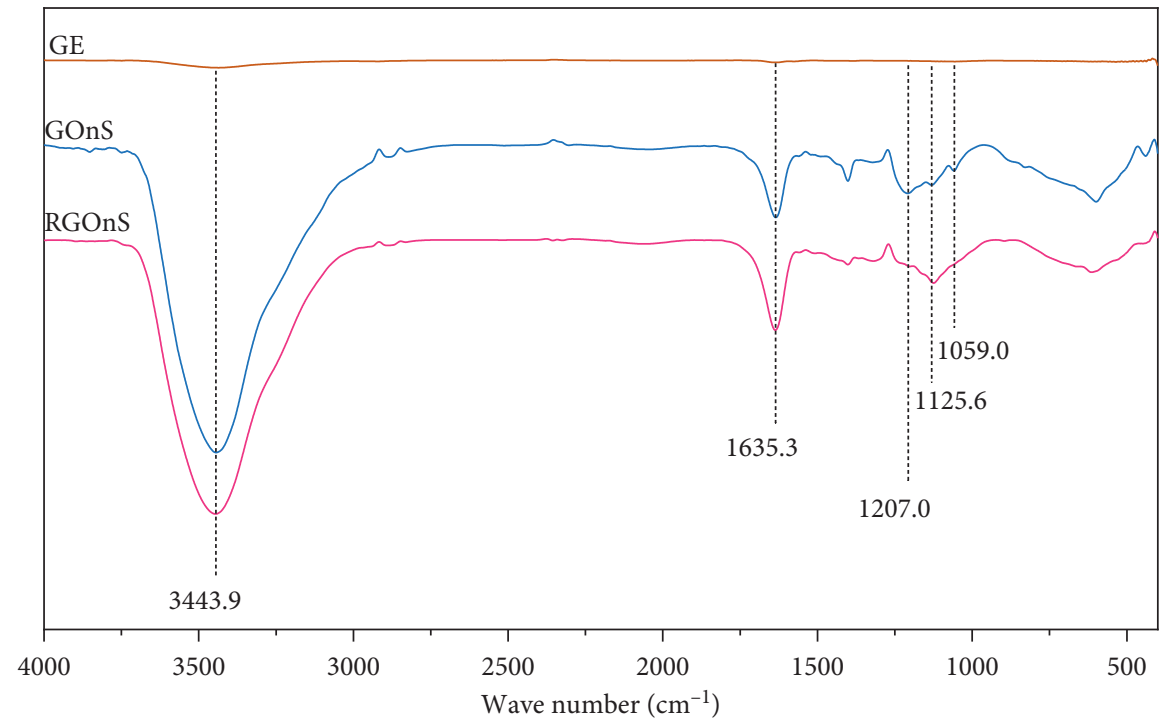

(b)

FIGURE 2: EDX (a) and FTIR (b) spectra of graphite, graphite oxide nanosheet electrode (GOnS), and reduced graphite oxide nanosheet electrode (RGOnS).

graphene oxide, which promotes the electron transfer process.

\subsection{Electrochemical Behavior of AMX on the Prepared} Electrode. The electrochemical behavior of AMX on graphite, GOnS, and RGOnS electrodes was investigated through their cyclic voltammograms (CVs) and square wave voltammograms (SWVs) as shown in Figure 4.

As can be seen in Figure 4(a) that in the PBS containing $500 \mu \mathrm{M}$ AMX, well-defined peaks appeared at $0.52 \mathrm{~V}$ in the forward scan of CVs of both graphite and RGOnS electrodes. These peaks correspond to the electrochemical oxidation of AMX on the electrode surface. The nonobservation of the reduction peak at reverse scan indicates that the electrochemical behavior of amoxicillin on these electrodes is irreversible. Meanwhile, the GOnS electrode's $\mathrm{CV}$ exhibited an unclear peak. This can be explained by the low electron transfer and high charge-transfer resistance that were caused by the high content of oxygen-containing functional groups on the graphite oxide surface, as confirmed by FTIR [48, 49]. After GOnS underwent a reduction process to form RGOnS, the oxygen-group content was eliminated, and defects on GOnS were repaired to restore the long-range conjugated network. Thus, the conductivity of RGOnS was improved that promoted the 


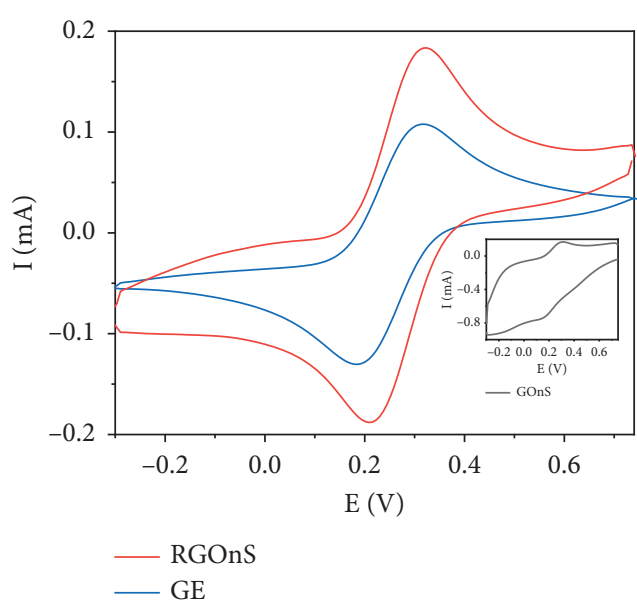

(a)

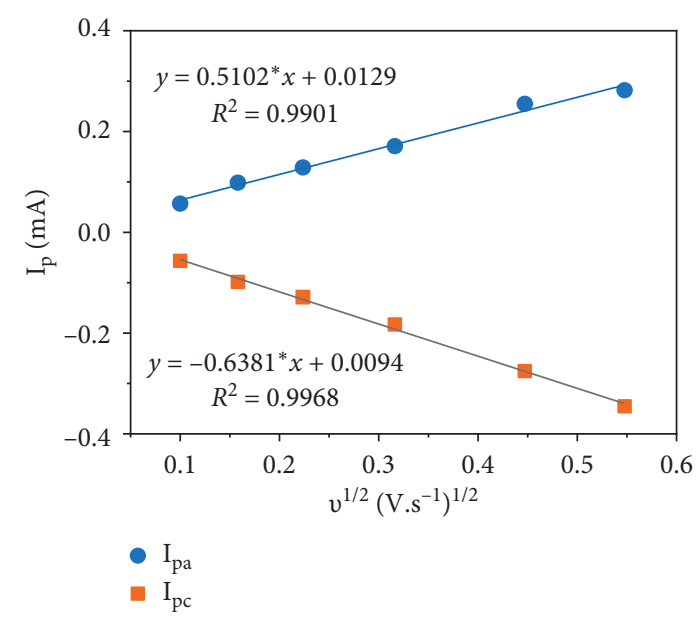

(b)

FIGURE 3: Cyclic voltammograms of graphite, reduced graphite oxide nanosheet electrodes, and graphite oxide nanosheet (inset) in $0.1 \mathrm{M}$ PBS (pH 7.0) containing $5 \mathrm{mM} \mathrm{K}_{3}\left[\mathrm{Fe}(\mathrm{CN})_{6}\right]$ at $v=100 \mathrm{mV} / \mathrm{s}(\mathrm{a})$ and the dependence of cathode and anode peak currents $\left(\mathrm{I}_{\mathrm{pa}}\right.$ and $\left.\mathrm{I}_{\mathrm{pc}}\right)$ on the square root of scan rate on RGOnS (b).

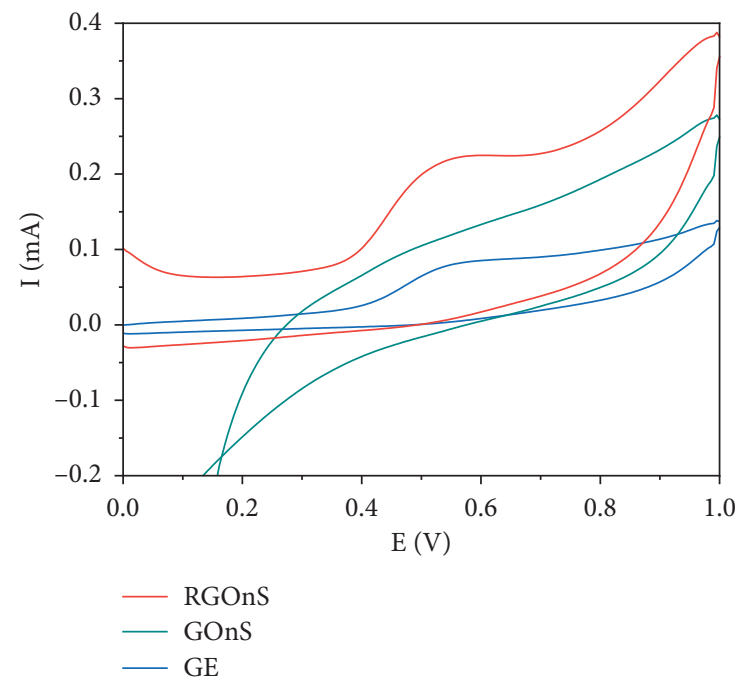

(a)

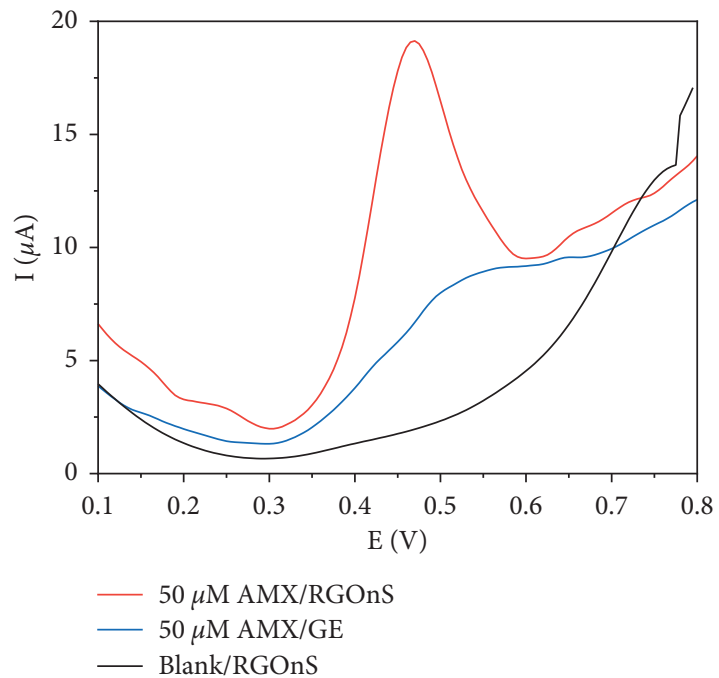

(b)

FIgure 4: Cyclic voltammograms in $500 \mu \mathrm{M}$ AMX solution at a scan rate of $50 \mathrm{mV} / \mathrm{s}$ (a) and square wave voltammograms in $50 \mu \mathrm{M}$ AMX solution with $120 \mathrm{~s}$ accumulation (b) of studied electrodes. The electrolyte is $0.1 \mathrm{M}$ PBS of pH 7.

electron transfer of the AMX oxidation on the electrode surface. However, RGOnS was not free of oxygen-containing functional groups such as $-\mathrm{COOH}$ and $-\mathrm{OH}$ on the reduced graphite sheets' edges that would facilitate the bonding with the analytes to induce the considerable enhancement of analytical signals [50-53]. The electrode surface improvement contributed to the significant increase in AMX signals. In particular, the SWV peak intensity of AMX on RGOnS after 120-s accumulation time of AMX is 9.7 times higher than that on the original graphite electrode (Figure 4(b)). Besides, the modified electrode also shows high electrocatalytic activity through the decrease of AMX overpotential in comparison with the original graphite electrode as seen in Figure 4(b).
3.4. Influence of GOnS Reduction Potential on the Signal of $A M X$. Regarding the reconstruction of the conjugated network in the RGOnS surface structure that affects the signal of AMX, the applied potential to reduce GOnS was investigated. In this experiment, the reduction potential $\left(\mathrm{E}_{\text {red }}\right)$ values ranging from $-0.2 \mathrm{~V}$ to $-1.5 \mathrm{~V}$ were examined for $120 \mathrm{~s}$.

As illustrated in Figure 5(a) and 5(b), when the applied potentials varied from -0.2 to $-1 \mathrm{~V}$, better peak currents of AMX were acquired. This can be explained by the better repair of the conjugated network on the RGOnS surface due to more reduction of $\mathrm{Csp}^{3}$ to $\mathrm{Csp}^{2}$ state at more negative reduction potentials, which facilitated the electron exchange and transfer in the network leading to the increase in the 


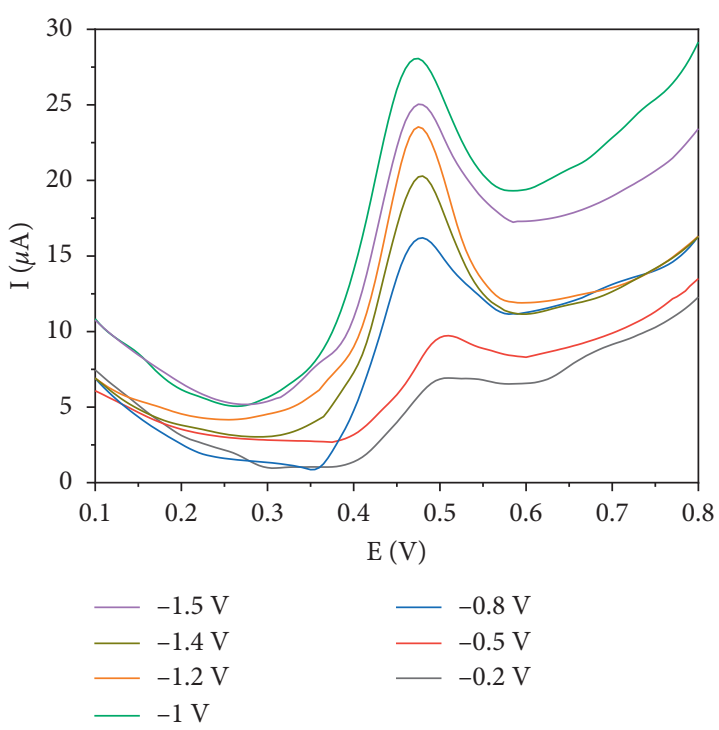

(a)

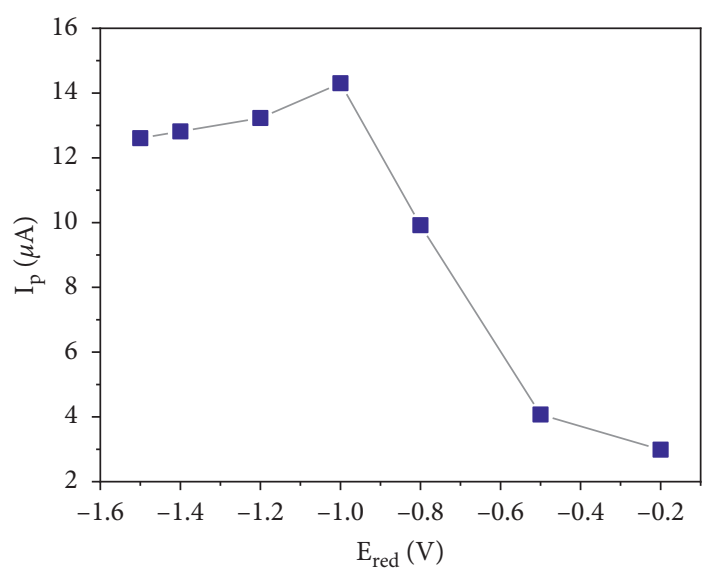

(b)

FIGURE 5: SWVs of RGOnS electrodes prepared at different $\mathrm{E}_{\text {red }}$ in PBS containing $50 \mu \mathrm{M}$ AMX (a) and plot of the AMX peak current $\left(I_{\mathrm{p}}\right)$ vs. $\mathrm{E}_{\text {red }}(\mathrm{b})$.

oxidation signal of AMX. The peak current reached the highest value as $\mathrm{E}_{\mathrm{red}}=-1 \mathrm{~V}$, and then it gradually decreased as $E_{\text {red }}$ was changed from $-1 \mathrm{~V}$ to $-1.5 \mathrm{~V}$. When the applied voltage was more negative than $-1 \mathrm{~V}$, the strong generation of $\mathrm{H}_{2}$ gas on the electrode surface occurred parallel to the reduction of oxygen-containing functional groups. This is believed to compete and restrict the reduction of $\mathrm{Csp}^{3}$ to $\mathrm{Csp}^{2}$. As a result, the regeneration of the $\pi$-conjugated network on the nanosheet at those reduction potentials was not efficient as at $\mathrm{E}_{\text {red }}$ of $-1 \mathrm{~V}$. Besides, with such negative potentials (from -1.2 to $-1.5 \mathrm{~V}$ ), the functional groups that facilitate the adsorption of the analyte may not be maintained in appropriate content. Therefore, $-1 \mathrm{~V}$ potential was chosen for GOnS reduction performance to get the highest signal of AMX.

\subsection{Optimization of Analysis Conditions}

3.5.1. Influence of electrolyte $p H$ on the signal of $A M X$. Figure 6(a) and 6(b) represents the influence of electrolyte $\mathrm{pH}$ in the range from 6.0 to 10.0 on the SWV signal of $50 \mu \mathrm{M}$ AMX in 0.1 M PBS. It is obvious that the AMX oxidation peak potential $\left(E_{\mathrm{p}}\right)$ shifted negatively with the increase of $\mathrm{pH}$ values, and a good linear relationship between these two parameters was shown in Figure 6(b) (blue color) with the linear regression equation: $E_{\mathrm{p}}=1.025-0.062 \mathrm{pH}$ $\left(R^{2}=0.9917\right)$. This result exhibits that the electrochemical oxidation of AMX was accompanied by proton transfer. The slope of $-0.062 \mathrm{~V} / \mathrm{pH}$ is close to the theoretical value of $-0.059 \mathrm{~V} / \mathrm{pH}$ given by the Nernstian equation with $n=1$ that indicates the equal number of protons and electrons transfer process $[54,55]$. This result is in consonance with previous studies [26, 27, 30, 56]. Accordingly, the electrochemical oxidation of AMX follows the mechanism as presented in Scheme 1.
As shown in Figure 6(b), the red line reveals that the peak intensity gradually increased with the rise of $\mathrm{pH}$ values; and the highest value was obtained at $\mathrm{pH}$ 9.0. Since the $\mathrm{pH}$ was adjusted to 10.0, the peak height experienced a significant decline. Thus, $\mathrm{pH} 9.0$ was used as the optimal $\mathrm{pH}$ for the next experiment.

3.5.2. Influence of accumulation time on the signal of AMX. The accumulation time $\left(t_{\mathrm{acc}}\right)$ of AMX on the electrode surface has a significant impact on the SWV signals of AMX. The $t_{\mathrm{acc}}$ was examined in the range of $0 \mathrm{~s}-600 \mathrm{~s}$ to acquire an appropriate time for the analytical process. The result in Figure 6(c) shows a gradual growth of AMX peak current when $t_{\mathrm{acc}}$ changed from $0 \mathrm{~s}$ to $240 \mathrm{~s}$ that indicated the rapid adsorption of AMX onto the electrode surface. With longer $t_{\mathrm{acc}}$ from $240 \mathrm{~s}$ to $600 \mathrm{~s}$, the AMX peak current experienced a decrease that attributed to the desorption of AMX on the electrode surface. Therefore, for further study, $t_{\mathrm{acc}}$ of $120 \mathrm{~s}$ was chosen as the adequate time to achieve wide linearity, high sensitivity, and timesaving.

3.6. Reproducibility of the RGOnS Electrode. The reproducibility of the electrode plays a crucial role in the analysis because there was a considerable decrease in the analyte signals after successive measurements, resulting from the oxidation products that partly covered the electrode surface. In this section, the reproducibility was evaluated through SWV responses for $50 \mu \mathrm{M}$ AMX oxidation of 10 RGOnS electrodes, which were prepared under the same condition (Figure $7(\mathrm{a})$ ). The calculated relative standard deviation (RSD) for ten measurements is $1.36 \%$, illustrating the acceptable reproducibility of the electrode. 


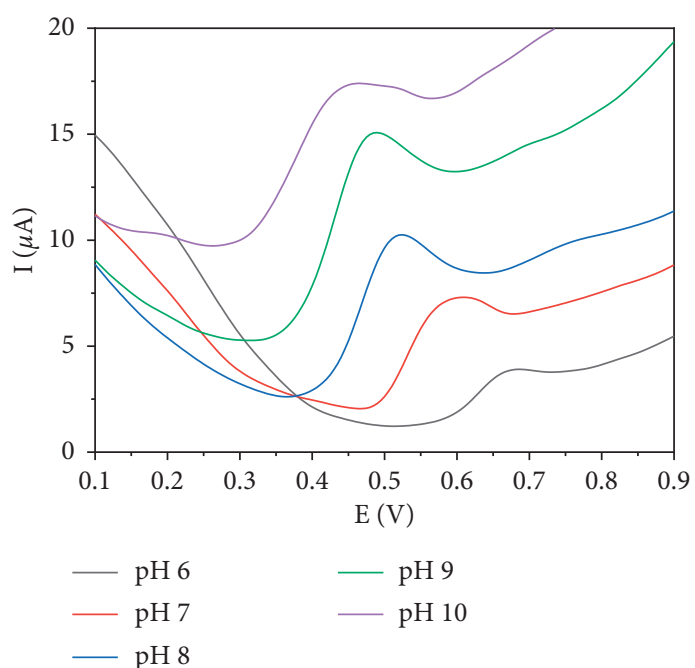

(a)

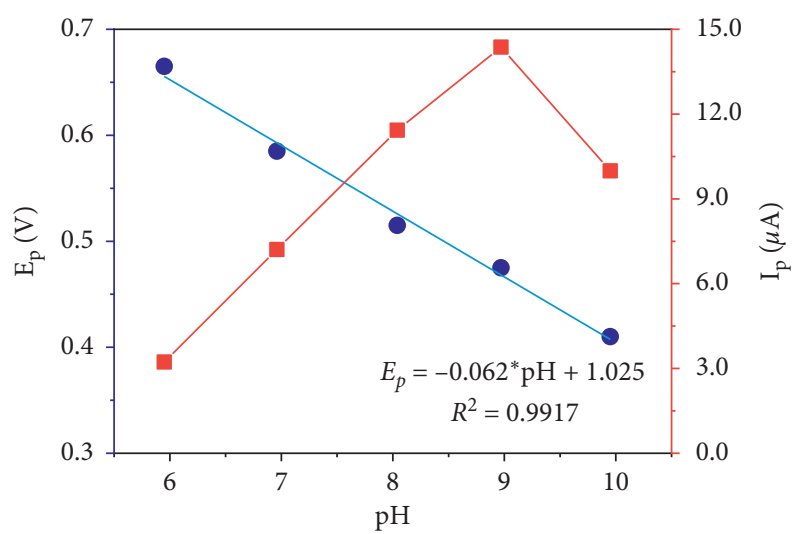

- $E_{p}$

$-\mathrm{I}_{\mathrm{p}}$

(b)

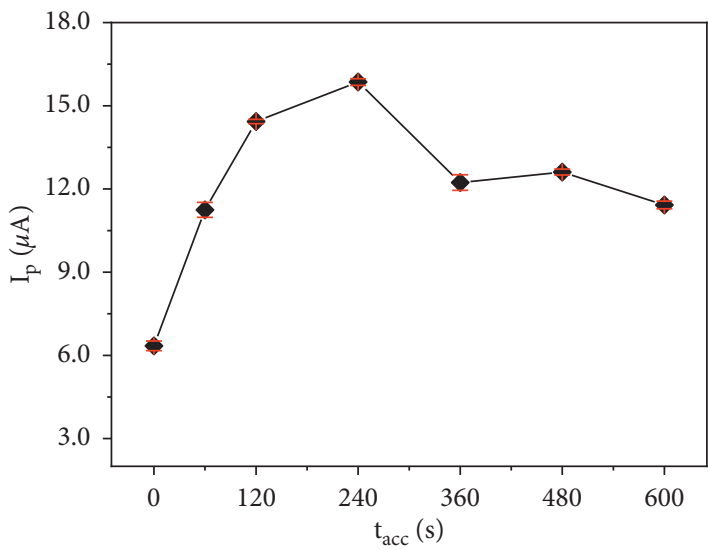

(c)

FIGURE 6: SWVs of RGOnS (with $E_{\text {red }}=-1 \mathrm{~V}$ in PBS containing $50 \mu \mathrm{M}$ AMX at different $\mathrm{pH}$ (a) and plot of the AMX peak potential and peak current vs. $\mathrm{pH}$ (b). Plot of AMX peak current vs. $t_{\mathrm{acc}}$ (c).<smiles>CC1(C)SC2C(NC(=O)C(N)C3C=CC(=O)C=C3)C(=O)N2C1C(=O)O</smiles>

Scheme 1: The Electrochemical oxidation process of amoxicillin.

3.7. Calibration Curve for AMX Detection. Figure 7(b) shows the electrochemical response of RGOnS for AMX oxidation in the concentration range of $0.5 \mu \mathrm{M}$ to $80 \mu \mathrm{M}$ under optimized conditions. It is observed that the anodic peak signal $\left(I_{\mathrm{p}}\right)$ varied linearly with the AMX concentration $\left(\mathrm{C}_{\mathrm{AMX}}\right)$. The linear regression equation was found as $I_{\mathrm{p}}$ $(\mu \mathrm{A})=0.8684+0.2770 \mathrm{C}_{\mathrm{AMX}}(\mu \mathrm{M})$ with the correlation coefficient of 0.9992 .

The limit of detection (LOD) determined using following the equation $\mathrm{LOD}=3 \sigma / \mathrm{b}$ was $0.193 \mu \mathrm{M}$, where $\sigma$ and $b$ are the standard deviation and the slope of the regression line for the range $0.5-5 \mu \mathrm{M}$, respectively. The calculated LOD was comparable with the ones reported in previous studies (Table 1) that confirmed the good sensitivity of the RGOnS electrode in AMX detection.

3.8. Determination of Amoxicillin in Different Water Samples. The practical performance of the RGOnS electrode was initially explored by the quantification of AMX in a drug 

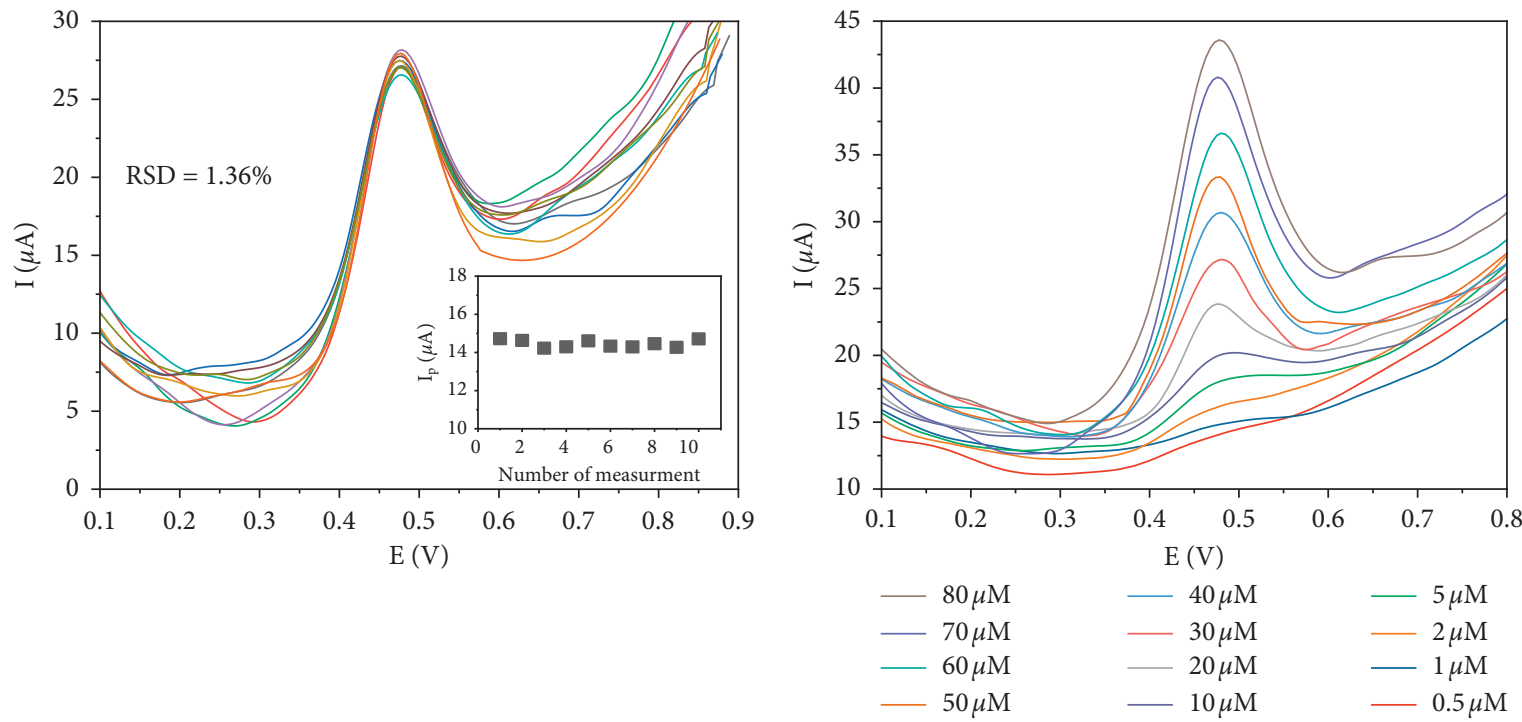

(a)

(b)

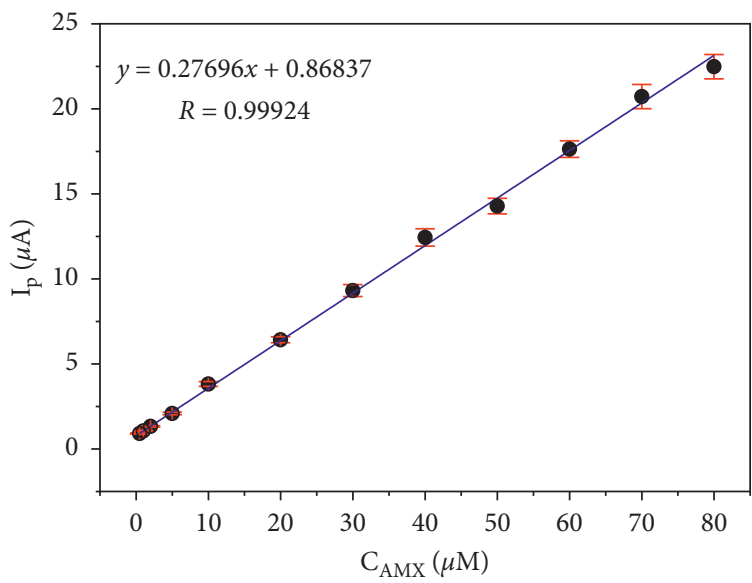

(c)

Figure 7: SWVs obtained on 10 different RGOnS electrodes at $50 \mu \mathrm{M}$ AMX (a), inset is AMX peak height in 10 measurements. The SWVs of AMX with concentration from 0.5 to $80 \mu \mathrm{M}$ (b) and calibration curve (c).

TABle 1: Comparison of the data obtained using electrochemical methods for the determination of amoxicillin.

\begin{tabular}{lcccc}
\hline Electrode & Method & Range $(\mu \mathrm{M})$ & LOD $(\mu \mathrm{M})$ & Ref. \\
\hline MWCNTs/GCE & CV & $0.6-8.0$ & 0.2 & 9 \\
AuNP-PdNP-ErGO & SWV & $30-350$ & 0.088 & {$[28]$} \\
CPE & CA & $0.195-14.6$ & 0.118 & {$[30]$} \\
PGA/3D-GE/GCE & SWV & $2-60$ & 0.92 & {$[57]$} \\
PGA/GLU/GCE & SWV & $2.0-25.0$ & 0.84 & {$[59]$} \\
Unmodified EPPG electrode & SWV & $5-500$ & 0.015 & {$[27]$} \\
AuNPs/en-MWCNTs/SPE & AdSV & $0.2-20$ & 0.193 & {$[29]$} \\
RGOnS & SWV & $0.5-80$ & Present work \\
\hline
\end{tabular}

SWV : square-wave voltammetry, ${ }^{*} \mathrm{DPV}$ : differential pulse voltammetry, ${ }^{*} \mathrm{CV}:$ cyclic voltammetry, ${ }^{*} \mathrm{CA}$ : chronoamperometric, ${ }^{*}$ AdSV : adsorptive stripping voltammetry, ${ }^{*} \mathrm{CPE}$ : carbon paste electrode, ${ }^{*} \mathrm{GCE}$ : glassy carbon electrode, ${ }^{*} \mathrm{PGA}$ : polyglutamic acid, * GLU: glutaraldehyde, ${ }^{*} \mathrm{EPPG}$ : edge plane pyrolytic graphite, ${ }^{*} \mathrm{NP}$ : nanoparticles, ${ }^{*} \mathrm{SPE}$ : screen printed electrode. 
TABLE 2: Analytical results for the electrochemical determination of amoxicillin $(n=3)$ using the RGOnS electrode in different water samples.

\begin{tabular}{|c|c|c|c|c|}
\hline \multirow{2}{*}{ Sample } & \multicolumn{2}{|c|}{$\mathrm{C}_{\mathrm{AMX}}(\mu \mathrm{M})$} & \multirow{2}{*}{ Recovery (\%) } & \multirow{2}{*}{ RSD (\%) } \\
\hline & Added conc. & Found conc. & & \\
\hline \multirow{3}{*}{ Distilled water } & 0 & n.d. & - & - \\
\hline & 5 & 5.10 & 102.0 & 2.5 \\
\hline & 10 & 10.26 & 102.6 & 3.1 \\
\hline \multirow{3}{*}{ Tap water } & 0 & n.d. & - & - \\
\hline & 5 & 5.15 & 103.0 & 3.6 \\
\hline & 10 & 10.15 & 101.5 & 4.0 \\
\hline \multirow{3}{*}{ West lake water } & 0 & n.d. & - & - \\
\hline & 5 & 5.21 & 104.2 & 3.5 \\
\hline & 10 & 10.68 & 106.8 & 4.8 \\
\hline \multirow{3}{*}{ Domestic wastewater } & 0 & n.d & - & - \\
\hline & 5 & 4.72 & 94.36 & 4.7 \\
\hline & 10 & 10.47 & 104.71 & 4.2 \\
\hline \multirow[b]{2}{*}{ Drug } & Nominal value (mg/capsule) & Found value (mg/capsule) & & \\
\hline & 500 & 477 & 95.0 & 3.3 \\
\hline
\end{tabular}

capsule and in spiked water samples. The determination of AMX in each sample was performed 3 times to estimate the relative standard deviation (RSD). The recoveries were also calculated for determined concentrations of AMX as described in Table 2.

\section{Conclusions}

An efficient RGOnS sensor for AMX detection was successfully achieved from pristine graphite by the electrochemical method. Thanks to the formation of reduced graphite oxide nanosheet, the modified electrode showed a larger electrochemical active surface area, faster charge transfer, and more effective catalytic activity compared with those on the original electrode. These characteristics significantly contributed to the enhancement of the sensitivity of AMX detection with a low LOD of $0.193 \mu \mathrm{M}$. SWV responses on the RGOnS electrode show good linearity between peak current and AMX concentration and the noticeable reproducibility. The developed electrode was effectively applied in the quantification of AMX in real samples with good recoveries.

\section{Data Availability}

The data used to support the findings of this study are included within the article.

\section{Conflicts of Interest}

The authors declare that they have no conflicts of interest.

\section{Acknowledgments}

This research was funded by the Vietnam National Foundation for Science and Technology Development (NAFOSTED) under grant no. 104.06-2019.27.

\section{References}

[1] A. Huttner, J. Bielicki, M. N. Clements et al., "Oral amoxicillin and amoxicillin-clavulanic acid: properties, indications and usage," Clinical Microbiology and Infection, vol. 26, no. 7, pp. 871-879, 2020.

[2] T. Heikkinen, O. Ruuskanen, T. Ziegler, M. Waris, and H. Puhakka, "Short-term use of amoxicillin-clavulanate during upper respiratory tract infection for prevention of acute otitis media," The Journal of Pediatrics, vol. 126, no. 2, pp. 313-316, 1995.

[3] J. Embree, "High dose amoxicillin: Rationale for use in otitis media treatment failures," Paediatrics and Child Health, vol. 4, no. 5, pp. 321-323, 1999.

[4] S. A. McEwen and P. J. Fedorka-Cray, "Antimicrobial use and resistance in animals," Clinical Infectious Diseases, vol. 34, no. s3, pp. S93-S106, 2002.

[5] S. Kuppusamy, D. Kakarla, K. Venkateswarlu, M. Megharaj, Y.-E. Yoon, and Y. B. Lee, "Veterinary antibiotics (VAs) contamination as a global agro-ecological issue: a critical view," Agriculture, Ecosystems and Environment, vol. 257, pp. 47-59, 2018.

[6] T. P. Van Boeckel, C. Brower, M. Gilbert et al., "Global trends in antimicrobial use in food animals," Proceedings of the National Academy of Sciences, vol. 112, no. 18, pp. 5649-5654, 2015.

[7] J. P. Bound and N. Voulvoulis, "Pharmaceuticals in the aquatic environment--a comparison of risk assessment strategies," Chemosphere, vol. 56, no. 11, pp. 1143-1155, 2004.

[8] M. I. Bailón-Pérez, A. M. García-Campaña, C. Cruces-Blanco, and M. del Olmo Iruela, "Trace determination of $\beta$-lactam antibiotics in environmental aqueous samples using off-line and on-line preconcentration in capillary electrophoresis," Journal of Chromatography A, vol. 1185, no. 2, pp. 273-280, 2008.

[9] I. Anastopoulos, I. Pashalidis, A. G. Orfanos et al., "Removal of caffeine, nicotine and amoxicillin from (waste)waters by various adsorbents. A review," Journal of Environmental Management, vol. 261, Article ID 110236, 2020. 
[10] T. Li, D. Teng, R. Mao, Y. Hao, X. Wang, and J. Wang, "A critical review of antibiotic resistance in probiotic bacteria," Food Research International, vol. 136, Article ID 109571, 2020.

[11] I. Gozlan, A. Rotstein, and D. Avisar, "Amoxicillin-degradation products formed under controlled environmental conditions: identification and determination in the aquatic environment," Chemosphere, vol. 91, no. 7, pp. 985-992, 2013.

[12] K. Kümmerer, "Antibiotics in the aquatic environment - a review - Part I," Chemosphere, vol. 75, no. 4, pp. 417-434, 2009.

[13] M. Gülfen, Y. Canbaz, and A. Özdemir, "Simultaneous determination of amoxicillin, lansoprazole, and levofloxacin in pharmaceuticals by HPLC with UV-Vis detector," Journal of Analysis and Testing, vol. 4, no. 1, pp. 45-53, 2020.

[14] V. Homem, A. Alves, and L. Santos, "Development and Validation of a fast procedure to analyze amoxicillin in river waters by direct-injection LC-MS/MS," Journal of Chemical Education, vol. 91, no. 11, pp. 1961-1965, 2014.

[15] C. Zhang, J. Zeng, W. Xiong, and Z. Zeng, "Rapid determination of amoxicillin in porcine tissues by UPLC-MS/MS with internal standard," Journal of Food Composition and Analysis, vol. 92, p. 103578, 2020.

[16] X. Xie and Z. Song, "Ultrasensitive determination of amoxicillin using chemiluminescence with flow injection analysis," Spectroscopy, vol. 20, Article ID 270417, 2006.

[17] C. Yang, M. E. Denno, P. Pyakurel, and B. J. Venton, "Recent trends in carbon nanomaterial-based electrochemical sensors for biomolecules: a review," Analytica Chimica Acta, vol. 887, pp. 17-37, 2015.

[18] E. Bernalte, S. Arévalo, J. Pérez-Taborda et al., "Rapid and onsite simultaneous electrochemical detection of copper, lead and mercury in the Amazon river," Sensors and Actuators B: Chemical, vol. 307, Article ID 127620, 2020.

[19] N. A. Yusof, S. F. Abd Rahman, and A. Muhammad, "Chapter 9 - carbon nanotubes and graphene for sensor Technology," in Synthesis, Technology and Applications of Carbon Nanomaterials, S. A. Rashid, R. N. I. Raja Othman, and M. Z. Hussein, Eds., pp. 205-222, Elsevier, Chennai, Tamilnadu, 2019.

[20] B. Han, M. Pan, X. Liu, J. Liu, T. Cui, and Q. Chen, "Electrochemical detection for uric acid based on $\beta$-lactoglobulinfunctionalized multiwall carbon nanotubes synthesis with PtNPs nanocomposite," Materials, vol. 12, no. 2, p. 214, 2019.

[21] D. Branagan and C. B. Breslin, "Electrochemical detection of glucose at physiological $\mathrm{pH}$ using gold nanoparticles deposited on carbon nanotubes," Sensors and Actuators B: Chemical, vol. 282, pp. 490-499, 2019.

[22] A. Savk, B. Özdil, B. Demirkan et al., "Multiwalled carbon nanotube-based nanosensor for ultrasensitive detection of uric acid, dopamine, and ascorbic acid," Materials Science and Engineering: C, vol. 99, pp. 248-254, 2019.

[23] T.-W. Chen, U. Rajaji, S.-M. Chen et al., "Facile synthesis of copper(II) oxide nanospheres covered on functionalized multiwalled carbon nanotubes modified electrode as rapid electrochemical sensing platform for super-sensitive detection of antibiotic," Ultrasonics Sonochemistry, vol. 58, Article ID 104596, 2019.

[24] S. Jafari, M. Dehghani, N. Nasirizadeh, M. H. Baghersad, and M. Azimzadeh, "Label-free electrochemical detection of Cloxacillin antibiotic in milk samples based on molecularly imprinted polymer and graphene oxide-gold nanocomposite," Measurement, vol. 145, pp. 22-29, 2019.

[25] M. Govindasamy, S.-F. Wang, S. Kumaravel, R. J. Ramalingam, and H. A. Al-lohedan, "Facile synthesis of copper sulfide decorated reduced graphene oxide nanocomposite for high sensitive detection of toxic antibiotic in milk," Ultrasonics Sonochemistry, vol. 52, pp. 382-390, 2019.

[26] A. Wong, A. M. Santos, F. H. Cincotto, F. C. Moraes, O. Fatibello-Filho, and M. D. P. T. Sotomayor, "A new electrochemical platform based on low cost nanomaterials for sensitive detection of the amoxicillin antibiotic in different matrices," Talanta, vol. 206, Article ID 120252, 2020.

[27] Rosy and R. N. Goyal, "Estimation of amoxicillin in presence of high concentration of uric acid and other urinary metabolites using an unmodified pyrolytic graphite sensor," Journal of The Electrochemical Society, vol. 162, no. 1, pp. G8-G13, 2015.

[28] B. Rezaei and S. Damiri, "Electrochemistry and adsorptive stripping voltammetric determination of amoxicillin on a multiwalled carbon nanotubes modified glassy carbon electrode," Electroanalysis, vol. 21, no. 14, pp. 1577-1586, 2009.

[29] A. Muhammad, N. Yusof, R. Hajian, and J. Abdullah, "Construction of an electrochemical sensor based on carbon nanotubes/gold nanoparticles for trace determination of amoxicillin in bovine milk," Sensors, vol. 16, no. 1, p. 56, 2016.

[30] N. Kumar, R. N. Rosy, and R. N. Goyal, "Gold-palladium nanoparticles aided electrochemically reduced graphene oxide sensor for the simultaneous estimation of lomefloxacin and amoxicillin," Sensors and Actuators B: Chemical, vol. 243, pp. 658-668, 2017.

[31] T. M. Prado, F. H. Cincotto, F. C. Moraes, and S. A. S. Machado, "Electrochemical sensor-based Ruthenium nanoparticles on reduced graphene oxide for the simultaneous determination of ethinylestradiol and amoxicillin," Electroanalysis, vol. 29, no. 5, pp. 1278-1285, 2017.

[32] P. B. Deroco, R. C. Rocha-Filho, and O. Fatibello-Filho, "A new and simple method for the simultaneous determination of amoxicillin and nimesulide using carbon black within a dihexadecylphosphate film as electrochemical sensor," Talanta, vol. 179, pp. 115-123, 2018.

[33] X. Yue, Z. Li, and S. Zhao, "A new electrochemical sensor for simultaneous detection of sulfamethoxazole and trimethoprim antibiotics based on graphene and $\mathrm{ZnO}$ nanorods modified glassy carbon electrode," Microchemical Journal, vol. 159, Article ID 105440, 2020.

[34] Z.-N. Huang, Z. Jiao Zou, J. Teng et al., "A novel electrochemical sensor based on self-assembled platinum nanochains - multi-walled carbon nanotubes-graphene nanoparticles composite for simultaneous determination of dopamine and ascorbic acid," Ecotoxicology and Environmental Safety, vol. 172, pp. 167-175, 2019.

[35] M. F. Hossain and G. Slaughter, "PtNPs decorated chemically derived graphene and carbon nanotubes for sensitive and selective glucose biosensing," Journal of Electroanalytical Chemistry, vol. 861, Article ID 113990, 2020.

[36] K. Z. Mousaabadi, A. A. Ensafi, H. Hadadzadeh, and B. Rezaei, "Reduced graphene oxide and carbon nanotubes composite functionalized by azobenzene, characterization and its potential as a curcumin electrochemical sensor," Journal of Electroanalytical Chemistry, vol. 873, Article ID 114418, 2020.

[37] L. Jiang, I. Santiago, and J. Foord, "Nanocarbon and nanodiamond for high performance phenolics sensing," Communications Chemistry, vol. 1, no. 1, p. 43, 2018.

[38] K. Parvez, R. Li, S. R. Puniredd et al., "Electrochemically exfoliated graphene as solution-processable, highly conductive electrodes for organic electronics," ACS Nano, vol. 7, no. 4, pp. 3598-3606, 2013. 
[39] K. Parvez, Z.-S. Wu, R. Li et al., "Exfoliation of graphite into graphene in aqueous solutions of inorganic salts," Journal of the American Chemical Society, vol. 136, no. 16, pp. 60836091, 2014.

[40] P. Yu, S. E. Lowe, G. P. Simon, and Y. L. Zhong, "Electrochemical exfoliation of graphite and production of functional graphene," Current Opinion in Colloid \& Interface Science, vol. 20, no. 5-6, pp. 329-338, 2015.

[41] R. Lan, W. Su, and J. Li, "Preparation and catalytic performance of expanded graphite for oxidation of organic pollutant," Catalysts, vol. 9, no. 3, p. 280, 2019.

[42] H. M. A. Asghar, S. N. Hussain, H. Sattar, N. W. Brown, and E. P. L. Roberts, "Environmentally friendly preparation of exfoliated graphite," Journal of Industrial and Engineering Chemistry, vol. 20, no. 4, pp. 1936-1941, 2014.

[43] S. C. Rattana, N. Witit-anun, S. Chaiyakun, N. Witit-anun, and C. K., P. Limsuwan, "Preparation and characterization of graphene oxide nanosheets," Procedia Engineering, vol. 32, pp. 759-764, 2012.

[44] D. Khalili, "Graphene oxide: a promising carbocatalyst for the regioselective thiocyanation of aromatic amines, phenols, anisols and enolizable ketones by hydrogen peroxide/KSCN in water," New Journal of Chemistry, vol. 40, no. 3, pp. 2547-2553, 2016.

[45] V. H. Pham, T. V. Cuong, S. H. Hur et al., "Chemical functionalization of graphene sheets by solvothermal reduction of a graphene oxide suspension in N-methyl-2pyrrolidone," Journal of Materials Chemistry, vol. 21, no. 10, pp. 3371-3377, 2011.

[46] A. J. Bard and L. R. Faulkner, Electrochemical Methods: Fundamentals and Applications, John Wiley \& Sons, New York, NY, USA, 2nd edition, 2000.

[47] A. Ressine, C. Vaz-Domínguez, V. M. Fernandez et al., "Bioelectrochemical studies of azurin and laccase confined in three-dimensional chips based on gold-modified nano-/ microstructured silicon," Biosensors and Bioelectronics, vol. 25, no. 5, pp. 1001-1007, 2010.

[48] A. Martín and A. Escarpa, "Graphene: the cutting-edge interaction between chemistry and electrochemistry," TrAC Trends in Analytical Chemistry, vol. 56, pp. 13-26, 2014.

[49] Y. Tang, C. Sun, X. Yang, X. Yang, and R. F. Shen, "Graphene modified glassy carbon electrode for determination of trace aluminium(III) in biological samples," International Journal of Electrochemical Science, vol. 8, pp. 4194-4205, 2013.

[50] A. J. S. Ahammad, T. Islam, and M. M. Hasan, "Chapter 12 graphene-based electrochemical sensors for biomedical applications," in Biomedical Applications of Graphene and 2D Nanomaterials, M. Nurunnabi and J. R. McCarthy, Eds., pp. 249-282, Elsevier, Chennai, Tamilnadu, 2019.

[51] L. Chen, Y. Tang, K. Wang, C. Liu, and S. Luo, "Direct electrodeposition of reduced graphene oxide on glassy carbon electrode and its electrochemical application," Electrochemistry Communications, vol. 13, no. 2, pp. 133-137, 2011.

[52] X. Niu, W. Zheng, C. Yin et al., "Electrochemical DNA biosensor based on gold nanoparticles and partially reduced graphene oxide modified electrode for the detection of Listeria monocytogenes hly gene sequence," Journal of Electroanalytical Chemistry, vol. 806, pp. 116-122, 2017.

[53] S. Kochmann, T. Hirsch, and O. S. Wolfbeis, "Graphenes in chemical sensors and biosensors," TrAC Trends in Analytical Chemistry, vol. 39, pp. 87-113, 2012.

[54] C. Li, J. Xu, Y. Wu et al., "g-C3N4 nanofibers doped poly(3,4ethylenedioxythiophene) modified electrode for simultaneous determination of ascorbic acid and acetaminophen," Journal of Electroanalytical Chemistry, vol. 824, pp. 52-59, 2018.

[55] Q. Lian, Z. He, Q. He et al., "Simultaneous determination of ascorbic acid, dopamine and uric acid based on tryptophan functionalized graphene," Analytica Chimica Acta, vol. 823, pp. 32-39, 2014.

[56] S. Zeinali, H. Khoshsafar, M. Rezaei, and H. Bagheri, "Fabrication of a selective and sensitive electrochemical sensor modified with magnetic molecularly imprinted polymer for amoxicillin," Analytical and Bioanalytical Chemistry Research, vol. 5, no. 2, pp. 195-204, 2018.

[57] A. Hrioua, A. Farahi, S. Lahrich, M. Bakasse, S. Saqrane, and M. A. El Mhammedi, "Chronoamperometric detection of amoxicillin at graphite electrode using chelate effect of copper(II) ions: application in human blood and pharmaceutical tablets," ChemistrySelect, vol. 4, no. 28, pp. 8350-8357, 2019.

[58] C. Chen, X. Lv, W. Lei et al., "Amoxicillin on polyglutamic acid composite three-dimensional graphene modified electrode: reaction mechanism of amoxicillin insights by computational simulations," Analytica Chimica Acta, vol. 1073, pp. 22-29, 2019.

[59] D. P. Santos, M. F. Bergamini, and M. V. B. Zanoni, "Voltammetric sensor for amoxicillin determination in human urine using polyglutamic acid/glutaraldehyde film," Sensors and Actuators B: Chemical, vol. 133, no. 2, pp. 398-403, 2008. 